\title{
ESTUDO DO TEOR E COMPOSIÇÃO DO ÓLEO DE ALGUMAS VARIEDADES DE CAFE (Coffea arabica L.) *
}

\author{
HOMERO FONSECA ** \\ LUIZ E. GUTIERREZ ***
}

\begin{abstract}
No presente trabalho foram determinados os teores de extrato etéreo de 19 variedades de café, no estado verde, no torrado, nas bôrras de obtenção caseira da infusão e na bôrra de extração de café solúvel, bem como a fração insaponificável e composição em ácidos graxos de cada óleo. Foi calculada também uma correlação entre o teor de óleo e o extrato aquoso do café torrado.

Observou-se que o teor de óleo no café verde variou de 10 a $13 \%$; no café torrado de 12 a $17 \%$ e nas bôrras do processo caseiro de 7 a $13 \%$.

A fração insaponificável do óleo extraido variou de 2 a $5 \%$.

As percentagens dos ácidos graxos não variaram acentuadamente de uma variedade para outra, assim como do estado verde para o torrado podendo-se presumir que a torração pouco afetou êsses ácidos graxos. As diferenças foram maiores quando comparados os teores de ácidos graxos do café verde ou torrado com o das bôrras: observou-se um grande decréscimo do ácido palmítico e aumento dos ácidos olêico, esteárico, linolênico e araquídico. Foi verificada também uma correlação positiva entre o teor de óleo e o extrato aquoso do café torrad̦o.
\end{abstract}

\section{REVISÃO DA LITERATURA}

As pesquisas realizadas sôbre a composição do grão de café quanto ao teor de óleo e ácidos graxos foram efetuados por alguns pesquisadores.

LOCKHART (1957) estudando a composição do grão de café, apresenta os seguintes dados: matérias graxas, 4 a $12 \%$ e insaponificáveis, 0 a $2 \%$.

KAUFMANN \& HAMSAGAR (1962) estudaram óleos de diferentes tipos de café brasileiros e fizeram determinações de ácidos graxos por cromatografia em papel.

\footnotetext{
* Entregue para publicação em 30-12-1971.

** Departamento de Tecnologia Rural.

*** Bolsista da Fundação de Amparo à Pesquisa do E. de São Paulo.
} 
TANGO \& CARVALHO (1963) determinaram o teor de matérias graxas de diversas variedades de Coffea arabica e o teor de cafeina. graxos.

WURZIGER (1963) determinou alguns índices físicos e químicos do óleo de café verde e torrado, procurando correlacionar as diferenças com o estado geral do grão.

BARBIROLI (1966) estudou o efeito da torração industrial sôbre os ácidos graxos da gordura do café e concluiu que, em elevadas temperaturas de torração, os ácidos graxos mirístico, palmítico, esteárico e olêico sofrem aumento enquanto que palmitolêico, linolênico, behênico e araquídico sofrem redução.

Tendo em vista a escassa literatura existente, principalmente em variedades brasileiras resolvemos efetuar um estudo das matérias graxas em dezenove variedades da coleção do Instituto Agronômico de Campinas, estudo êssse abrangendo o teor de óleo, teor de insaponificáveis e composição em ácidos graxos.

\section{MATERIAL E MÉTODOS}

\section{Material}

Café verde: as amostras de grãos de café verde foram obtidas na secção de Genética do Instituto Agronômico de Campinas.

Café torrado: foi obtido por torração das amostras verdes.

Bôrras : as bôrras foram obtidas pelo preparo da infusão por processo caseiro, utilizando o café torrado. As bôrras industriais foram obtidas na fábrica de café solúvel FRUSOL S/A, de Campinas.

\section{Métodos}

Preparo da amostra verde: os grãos de café foram sêcos em estufa e moidos até grau de finura de 14-20 "mesh".

Preparo da amostra torrada: os grãos foram torrados em torradores Rod-Bell, à temperatura de $200-230^{\circ} \mathrm{C}$ por 10 a 20 minutos. Foram depois moidos em moinho "Lilla" mod. Junior de 85 discos até grau de finura de 14-20 "mesh".

Bôrras pelo processo caseiro : a 100 gramas de café torrado e moido foram adicionados $1000 \mathrm{ml}$ de água em ebulição. Filtrou-se. Secouse em estufa a $100^{\circ} \mathrm{C}$.

Teor de óleo : foi empregado o método da A.O.A.C. (1960), utilizando éter de petróleo $30-60^{\circ} \mathrm{C}$. Foram feitas 5 repetições. 
Fração insaponificável: foi usado também método da A.O.A.C. (1960) utilizando éter de petróleo $30-60^{\circ} \mathrm{C}$ para extração, após a saponificação do óleo. (1960).

Metilação de ácidos graxos : foi utilizado método de LUDDY et al

Ácidos graxos: os ácidos graxos foram detectados em cromatógrafo de gás marca CG mod. 15, nas seguintes condições :

fluxo do gás de arraste: $50 \mathrm{ml} / \mathrm{min}$

temperatura da coluna : $180-185^{\circ} \mathrm{C}$

temperatura do detector: $250^{\circ} \mathrm{C}$ (chama de Hidrogênio)

temperatura do vaporizador : $240^{\circ} \mathrm{C}$

Colunas gêmeas de $3 / 8$ de polegada de diâmetro interno por dois metros de comprimento

suporte: gás Chrom AW - DMCS

fase estacionária: DEGS (dietileno glicol succinato) a $18 \%$.

Foram feitas 5 determinações para cada óleo.

\section{RESULTADOS}

Os resultados obtidos são os constantes dos Quadros de números 1 a 9 .

\section{DISCUSSÃo}

Pelo quadro 1, podemos verificar que, as variedades de café estudadas, apresentaram pouca variação quanto ao teor de óleo nos diversos estados (verde, torrado e bôrras). Houve um aumento no teor de óleo do café verde para o torrado e uma diminuição do torrado para a bôrra. Essas variações são, provàvelmente devidas a :

a) durante a torração, ocorre pirólise de aminoácidos e outros compostos, com perda de água e gás carbônico. Os lipídios, porém, parecem sofrer muito pouco durante a torração, daí a razão de seu aumento relativo.

b) a diminuição do torrado para a bôrra é explicada pelo arraste de óleo durante o preparo da bebida, fato que ficou evidenciado, por algumas verificações que fizemos na infusão.

A fração insaponificável variou de 2 a $5 \%$, tendo aumentado do verde e torrado para as bôrras (quadro 2 ).

Existe uma correlação positiva $(r=+0,63)$ entre os teores de óleo do café torrado e do extrato aquoso, para as variedades estudadas (quadro 3). 
O teor de ácido palmítico no óleo de diversas variedades de café verde e torrado apresentou pouca variação, o que pode ser encontrado no quadro 4. Porém, há um sensivel decréscimo do seu teor do estado verde e torrado para as bôrras. Para explicar êsses fatos poderiamos sugerir que o torração tenha pequena influência na estabilidade do referido ácido graxo.

Observamos que o áciảo graxo de maior percentagem é sempre o linolêico, seguido do palmítico, olêico, esteárico, araquídico e linolênico (quadros de n.os 4 a 9). Êste resultado está de acôrdo com os encontrados por KAUFMAN \& HAMSAGAR (1962) e BARBIROLI (1966).

Os ácidos graxos esteárico, olêico, linolêico, linolênico e araquídico sofreram aumento do teor do café verde e torrado para as bôrras enquanto que o palmítico sofreu redução.

Observamos também, pelos resultados obtidos, que os teores de óleo e dos ácidos graxos nas bôrras pelo processo caseiro e industrial apresentam pouca diferença, embora os processos sejam distintos. Convém ressaltar que foram analisadas bôrras de apenas uma indústria de café solúvel.

Fizemos determinação do teor de óleo nas infusões obtidas durante o preparo das bôrras e encontramos uma variação de 0,10 a 0,30 gramas de óleo por $100 \mathrm{ml}$ de infusão.

\section{SUMMARY}

\section{YIELD AND COMPOSITION OF THE OIL OF SOME COFFEE (Coffea arabica L.) VARIETIES}

In the present work, the ether extract of green, roasted, home made coffee dregs of 19 varieties and of industrial soluble coffee dregs were determined. The insaponifiable fraction and fatty acid composition of the oil of each variety were also determined. A correlation between oil yield and aqueous extract was calculated.

The oil yield varied, from 10 to $13 \%$ in green coffee, from 12 to $17 \%$ in roasted and from 7 to $18 \%$ in home made coffee dregs.

.The insaponifiable fraction of the oils varied within 2 and $5 \%$.

It was not found a great variation in the fatty acid composition among varieties, and between green and roasted coffee as well. Major differences were observed when the fatty acid composition of green and roasted coffee was compared with that of the coffee dregs: it was observed a decrease in palmitic acid and an increase in oleic, stearic, linolenic and arachydic acid contents. 
A positive correlation was found between the oil yield and aqueous extract of roasted coffee.

\section{LITERATURA CITADA}

ASSOCIATION OF OFFICIAL AGRICULTURAL CHEMIST, 1960. Official Methods of Analysis, 9 th. ed. pp 182, 287, 372-73. Publicado pela A.O.A.C. Washington, D.C.

BARBIROLI, G., 1966. Transformation of Fatty Substances in Coffee During Industrial Roasting. Quad. Merceol., 5(2):223-35.

KAUFMANN, H. P. \& R. S. HAMSAGAR, 1962. Component Lipids of the Coffee bean. Fette, Seifen, Anstrichmittel, 64:206-13.

LOCKHART, E. E., 1963. The Chemistry of Roasted Coffee and the Beverage in Relation to Industry Requirements. Café, Cacao e Thé, 7:192-200.

LUDDY, F. E., 1960. Direct Conversion of Lipid Components to their Fatty Acid Methyl Esters. J. Am. Chem. Soc., 37:447.

TANGO, J. S. \& A. CARVALHO, 1963. Teor de óleo e de cafeína em variedades de café. Bragantia, 22: 793-798.

WURZIGER, J., 196\%. The Coffee Oil of Green and Roasted Coffee. Café, Cacao e Thé, $7: 331-40$ 
Quadro 1 - Teor de óleo de diversas variedades de café verde, torrado, das bôrras obtidas pelo processo caseiro e industrial (em \%).

\begin{tabular}{lcccc}
\hline Variedade & Verde & Torrado & $\begin{array}{c}\text { Bôrra } \\
\text { Caseiro }\end{array}$ & $\begin{array}{c}\text { Bôrra } \\
\text { Industriai }\end{array}$ \\
\hline \hline Mundo Novo LCP & 11,08 & 15,15 & 12,82 & 14,35 \\
Miundo Novo LCMP & 12,18 & 14,42 & 11,20 & \\
Bourbon Amarelo & 12,01 & 16,32 & 14,20 & \\
Bourbon Vermelho & 13,20 & 16,28 & 15,15 & \\
Caturra Amarelo & 12,05 & 17,24 & 18,19 & \\
S. Bernardo & 10,76 & 14,53 & 11,28 & \\
Anormalis & 12,27 & 17,11 & 11,35 & \\
Volutifolia & 11,48 & 15,33 & 11,70 & \\
Semperflorens & 10,98 & 12,95 & 10,12 & \\
Amarelo & 12,06 & 13,76 & 9,31 & \\
Maragogipe & 12,46 & 14,70 & 8,74 & \\
Mokka & 10,89 & 15,17 & 7,94 & \\
Abramulosa AR & 12,23 & 15,06 & 12,22 & \\
Abramulosa AR & 12,71 & 16,66 & 10,90 & \\
Mucronata & 10,82 & 15,60 & 10,65 & \\
Sumatra & 11,63 & 15,05 & 10,20 & \\
Acayá & 11,87 & 13,39 & 10,89 & \\
Angustifolia & 12,21 & 16,13 & 13,05 & \\
EP - 47 1132-2 & 11,18 & 15,35 & 11,76 & \\
\hline
\end{tabular}

Quadro 2 - Fração insaponificável do óleo de diversas variedades de café verde, torrado, das bôrras obtidas pelo processo caseiro e industrial ( $\mathrm{g} / 100 \mathrm{~g}$ de óleo $)$.

\begin{tabular}{lcccc}
\hline Variedade & Verde & Torrado & $\begin{array}{c}\text { Bôrra } \\
\text { Caseiro }\end{array}$ & $\begin{array}{c}\text { Bôrra } \\
\text { Industrial }\end{array}$ \\
\hline \hline Mundo Novo LCP & 4,08 & 3,00 & 4,59 & 3,54 \\
Mundo Novo LCMP & 3,49 & 3,33 & 4,36 & \\
Bourbon Amarelo & 3,53 & 2,68 & 4,00 & \\
Bourbon Vermelho & 5,32 & 2,98 & 4,29 & \\
Caturra Amarelo & 5,86 & 4,45 & 2,80 & \\
S. Bernardo & 3,49 & 3,09 & 3,23 & \\
Anormalis & 3,34 & 2,14 & 3,43 & \\
Volutifolia & 2,37 & 2,33 & 3,82 & \\
Semperflorens & 3,55 & 2,87 & 4,89 & \\
Amarelo & 2,82 & 2,38 & 2,64 & \\
Maragogipe & 3,22 & 2,00 & 4,02 & \\
Mokka & 5,10 & 2,30 & 4,28 & \\
Abramulosa AR & 2,67 & 2,75 & 4,33 & \\
Abramulosa AR & 3,02 & 2,87 & 4,01 & \\
Mucronata & 3,13 & 3,57 & 3,32 & \\
Sumatra & 2,61 & 2,01 & 4,13 & \\
Acayá & 3,35 & 3,33 & 4,87 & \\
Angustifolia & 3,86 & 3,01 & 2,89 & \\
EP - 47 1132-2 & 2,59 & 2,15 & 5,54 & \\
\hline
\end{tabular}


Quadro 3 - Percentagens de extrato aquoso e de óleo de diversas variedades de café torrado $(\mathrm{p} / \mathrm{p})$.

\begin{tabular}{lcc}
\hline Variedade & \% óleo & Extrato Aquoso \\
\hline \hline Mundo Novo LCP & 15,15 & 25,00 \\
Mundo Novo LCMP & 14,42 & 22,44 \\
Bourbon Amarelo & 16,32 & 27,05 \\
Bourbon Vermelho & 16,28 & 27,92 \\
Caturra Amarelo & 17,24 & 25,88 \\
S. Bernardo & 14,53 & 23,75 \\
Anormalis & 17,11 & 23,58 \\
Volutifolia & 15,33 & 22,74 \\
Semperflorens & 12,95 & 23,25 \\
Amarelo & 13,76 & 19,07 \\
Maragogipe & 14,70 & 22,82 \\
Mokka & 15,17 & 23,45 \\
Abramulosa AR & 15,06 & 25,22 \\
Abramulosa AR & 16,66 & 25,70 \\
Mucronata & 15,60 & 27,13 \\
Sumatra & 15,05 & 28,01 \\
Acayá & 13,39 & 23,12 \\
Angustifolia & 16,13 & 27,03 \\
EP - 47 1132 - 2 & 15,35 & 24,10 \\
\hline \multicolumn{2}{c}{ Obs. - Coeficiente de correlação $=+0,63$} &
\end{tabular}

Quadro 4 - Teor de ácido palmítico do óleo de diversas variedades de café verde, torrado e das bôrras pelo processo caseiro e industrial (\% em pêso do total de ácidos graxos).

\begin{tabular}{lcccc}
\hline Variedade & Verde & Torrado & $\begin{array}{c}\text { Bôrra } \\
\text { Caseiro }\end{array}$ & $\begin{array}{c}\text { Bôrra } \\
\text { Industrial }\end{array}$ \\
\hline \hline Mundo Novo LCP & 33,25 & 35,07 & 20,40 & 23,25 \\
Mundo Novo LCMP & 38,10 & 41,11 & 20,20 & \\
Bourbon Amarelo & 35,40 & 38,35 & 18,87 & \\
Bourbon Vermelho & 36,28 & 39,50 & 22,80 & \\
Caturra Amarelo & 34,62 & 36,73 & 19,27 & \\
S. Bernardo & 35,90 & 38,81 & 17,15 & \\
Anormalis & 39,84 & 42,98 & 20,83 & \\
Volutifolia & 34,07 & 38,09 & 20,61 & \\
Semperflorens & 32,12 & 35,18 & 22,72 & \\
Amarelo & 38,78 & 42,12 & 20,00 & \\
Maragogipe & 33,22 & 36,08 & 20,90 & \\
Mokka & 38,25 & 41,25 & 24,78 & \\
Abramulosa AR & 29,67 & 34,25 & 22,22 & \\
Abramulosa AR & 36,70 & 40,01 & 25,07 & \\
Mucronata & 38,22 & 40,53 & 20,00 & \\
Sumatra & 31,47 & 35,02 & 23,84 & \\
Acayá & 41,24 & 43,55 & 19,30 & \\
Angustifolia & 39,64 & 42,57 & 20,90 & \\
EP - 47 1132-2 & 36,72 & 39,91 & 20,47 & \\
\hline
\end{tabular}


Quadro 5 - Teor de ácido esteárico do óleo de diversas variedades de café verde, torrado e das bôrras pelo processo caseiro e industrial (\% em pêso do total de ácidos graxos).

\begin{tabular}{lcccc}
\hline Variedade & Verde & Torrado & $\begin{array}{c}\text { Bôrra } \\
\text { Caseiro }\end{array}$ & $\begin{array}{c}\text { Bôrra } \\
\text { Industrial }\end{array}$ \\
\hline \hline Mundo Novo LCP & 5,50 & 5,72 & 13,97 & 15,55 \\
Mundo Novo LCMP & 5,30 & 5,65 & 15,10 & \\
Bourbon Amarelo & 5,78 & 6,72 & 13,42 & \\
Bourbon Vermelho & 6,30 & 6,85 & 16,00 & \\
Caturra Amarelo & 6,12 & 6,50 & 13,20 & \\
Acayá & 4,40 & 4,81 & 11,69 & \\
EP - 47 1132 - & 5,38 & 5,70 & 13,25 & \\
Anormalis & 3,79 & 4,52 & 12,50 & \\
Volutifolia & 5,37 & 6,01 & 13,78 & \\
Semperflorens & 6,20 & 6,66 & 14,20 & \\
Mokka & 5,70 & 6,32 & 9,09 & \\
Amarelo & 4,26 & 5,20 & 12,77 & \\
S. Bernardo & 6,94 & 5,35 & 15,89 & \\
Maragogipe & 7,12 & 7,33 & 14,15 & \\
Sumatra & 7,02 & 6,57 & 13,00 & \\
Mucronata & 5,67 & 6,60 & 15,52 & \\
Abramulosa AR & 5,50 & 6,25 & 11,45 & \\
Abramulosa AR & 6,27 & 6,03 & 11,80 & \\
Angustifolia & 4,57 & 4,87 & 13,25 & \\
\hline
\end{tabular}

Quadro 6 - Teor de ácido olêico do óleo de diversas variedades de café verde, torrado e das bôrras pelo processo caseiro e industrial (\% em pêso do total de ácidos graxos).

\begin{tabular}{lcccc}
\hline Variedade & Verde & Torrado & $\begin{array}{c}\text { Bôrra } \\
\text { Caseiro }\end{array}$ & $\begin{array}{c}\text { Bôrra } \\
\text { Industrial }\end{array}$ \\
\hline \hline Mundo Novo LCP & 5,87 & 5,81 & 14,12 & 14,30 \\
Mundo Novo LCMP & 6,47 & 5,90 & 15,70 & \\
Bourbon Amarelo & 6,06 & 6,85 & 14,12 & \\
Bourbon Vermelho & 7,06 & 6,90 & 13,00 & \\
Caturra Amarelo & 6,75 & 6,50 & 14,40 & \\
Acayá & 5,60 & 5,02 & 13,20 & \\
EP 47 1132 - & 6,56 & 6,13 & 15,65 & \\
Anormalis & 4,21 & 5,09 & 15,62 & \\
Volutifolia & 6,37 & 6,20 & 15,51 & \\
Semperflorens & 6,56 & 7,15 & 17,60 & \\
Mokka & 5,55 & 5,13 & 11,57 & \\
Amarelo & 4,74 & 5,55 & 14,44 & \\
S. Bernardo & 7,12 & 6,88 & 16,60 & \\
Maragogipe & 6,37 & 7,95 & 14,15 & \\
Sumatra & 6,90 & 6,82 & 15,30 & \\
Mucronata & 5,95 & 5,31 & 16,26 & \\
Abramulosa AR & 5,92 & 6,20 & 13,00 & \\
Abramulosa AR & 6,60 & 6,72 & 14,80 & \\
Angustifolia & 4,24 & 4,55 & 14,80 & \\
\hline
\end{tabular}


Quadro 7 - Teor de ácido linolêico do óleo de diversas variedades de café verde, torrado e das bôrras pelo processo caseiro e industrial (\% em pêso do total de ácidos graxos).

\begin{tabular}{lcccc}
\hline Variedade & Verde & Torrado & $\begin{array}{c}\text { Bôrra } \\
\text { Caseiro }\end{array}$ & $\begin{array}{c}\text { Bôrra } \\
\text { Industrial }\end{array}$ \\
\hline \hline Mundo Novo LCP & 54,15 & 52,08 & 43,93 & 39,37 \\
Mundo Novo LCMP & 47,25 & 45,01 & 41,50 & \\
Bourbon Amarelo & 50,12 & 48,93 & 45,10 & \\
Bourbon Vermelho & 47,32 & 44,87 & 38,35 & \\
Caturra Amarelo & 49,35 & 47,22 & 44,57 & \\
Acayá & 46,94 & 45,03 & 48,77 & \\
EP - 47 1132-2 & 48,76 & 46,53 & 42,76 & \\
Anormalis & 49,94 & 45,58 & 43,75 & \\
Volutifolia & 51,45 & 48,07 & 41,90 & \\
Semperflorens & 52,84 & 49,03 & 38,07 & \\
Mokka & 48,80 & 46,05 & 47,93 & \\
Amarelo & 49,52 & 45,22 & 47,20 & \\
S. Bernardo & 47,40 & 45,95 & 38,48 & \\
Maragogipe & 50,97 & 46,29 & 43,39 & \\
Sumatra & 51,62 & 49,65 & 40,76 & \\
Mucronata & 48,00 & 45,55 & 39,80 & \\
Abramulosa AR & 55,82 & 50,98 & 47,70 & \\
Abramulosa AR & 48,50 & 45,75 & 42,45 & \\
Angustifolia & 49,62 & 46,02 & 44,16 & \\
\hline
\end{tabular}

Quadro 8 - Teor de ácido araquídico do óleo de diversas variedades de café verde, torrado e das bôrras pelo processo caseiro e industrial (\% em pêso do total de ácidos graxos).

\begin{tabular}{lcccc}
\hline Variedade & Verde & Torrado & $\begin{array}{c}\text { Bôrra } \\
\text { Caseiro }\end{array}$ & $\begin{array}{c}\text { Bôrra } \\
\text { Industrial }\end{array}$ \\
\hline \hline Mundo Novo LCP & 1,05 & 0,75 & 4,83 & 6,30 \\
Mundo Novo LCMP & 1,72 & 1,23 & 5,05 & \\
Bourbon Amarelo & 1,52 & 1,60 & 5,31 & \\
Bourbon Vermelho & 1,58 & 1,09 & 6,50 & \\
Caturra Amarelo & 1,92 & 1,73 & 6,00 & \\
Acayá & 0,92 & 0,98 & 4,00 & \\
EP - 47 1132 - & 1,40 & 1,20 & 4,28 & \\
Anormalis & 1,37 & 1,07 & 4,16 & \\
Volutifolia & 1,56 & 0,98 & 5,16 & \\
Semperflorens & 1,22 & 1,27 & 5,10 & \\
Mokka & 0,95 & 0,79 & 4,13 & \\
Amarelo & 1,50 & 1,28 & 4,10 & \\
S. Bernardo & 1,84 & 1,61 & 7,50 & \\
Maragogipe & 1,22 & 1,35 & 5,00 & \\
Sumatra & 1,60 & 1,30 & 4,60 & \\
Mucronata & 1,29 & 1,10 & 5,00 & \\
Abramulosa AR & 1,60 & 1,35 & 3,73 & \\
Abramulosa AR & 1,07 & 0,80 & 4,58 & \\
Angustifolia & 1,16 & 1,09 & 4,58 & \\
\hline
\end{tabular}


Quadro 9 - Teor de ácido linolênico do óleo de diversas variedades de café verde, torrado e das bôrras pelo processo caseiro e industrial (\% em pêso do total de ácidos graxos).

\begin{tabular}{lcccc}
\hline Variedade & Verde & Torrado & $\begin{array}{c}\text { Bôrra } \\
\text { Caseiro }\end{array}$ & $\begin{array}{c}\text { Bôrra } \\
\text { Industrial }\end{array}$ \\
\hline \hline Mundo Novo LCP & 0,57 & 0,54 & 2,68 & 1,50 \\
Mundo Novo LCMP & 1,05 & 1,08 & 2,80 & \\
Bourbon Amarelo & 1,00 & 1,55 & 3,14 & \\
Bourbon Vermelho & 1,14 & 0,73 & 3,00 & \\
Caturra Amarelo & 1,10 & 1,38 & 2,40 & \\
Acayá & 0,62 & 0,55 & 2,90 & \\
EP - 47 1132 - & 0,68 & 0,59 & 3,60 & \\
Anormalis & 0,60 & 0,79 & 3,12 & \\
Volutifolia & 0,94 & 0,56 & 2,80 & \\
Semperflorens & 0,94 & 0,81 & 2,22 & \\
Mokka & 0,65 & 0,50 & 2,47 & \\
Amarelo & 0,86 & 0,72 & 1,60 & \\
S. Bernardo & 0,66 & 1,44 & 3,70 & \\
Maragogipe & 0,95 & 0,93 & 2,40 & \\
Sumatra & 0,65 & 0,69 & 2,30 & \\
Mucronata & 0,74 & 0,99 & 3,17 & \\
Abramulosa AR & 1,37 & 1,02 & 1,86 & \\
Abramulosa AR & 0,75 & 0,63 & 1,72 & \\
Angustifolia & 0,66 & 0,88 & 2,29 & \\
\hline
\end{tabular}

